\title{
Public Diplomacy in the Global Age: Lessons from Literature and Practice
}

\author{
Dr. Virimai Victor Mugobo
}

Lecturer, Faculty of Business, Cape Peninsula University of Technology (CPUT), Engineering Building,

Cape Town Campus, P. O. Box 652 Cape Town, 8000, South Africa

Email: mugobov@cput.ac.za

\section{Doi:10.5901/mjss.2014.v5n27p42}

\section{Abstract}

The rise of globalism, particularly information technology and massive flows of international communications, has ignited gigantic competition among nations for markets, foreign direct investment, tourists, human skills, innovation and an edge in international relations. This new phenomenon poses unprecedented challenges to the concept and practice of public diplomacy. This paper seeks to interrogate the concept and practice of public diplomacy in contemporary times, identify the challenges and recommend future direction. It focuses on how public diplomacy can influence global business for the socioeconomic benefit of African nations in general and South Africa in particular. Today, countries have become "brands" that must be created, nurtured and managed in a sustainable way through the creation of long-term and mutually beneficial relationships with bilateral and multi-lateral partners. Traditionally, public diplomacy mainly focused on the cultivation of stable political relationships among nations. However, public diplomacy now embraces the essence of a nation, be it political, economic, or, socio-cultural, not only to other governments but also to a multitude of other stakeholders such as foreign publics, multinational corporations, international media and non-governmental organisations. It is this emerging phenomenon that calls for the harnessing and integration of public diplomacy with nation branding in order to build, nurture and sustain a nation brand that enjoys positive relations with other countries, attracting inward investment and skills, promoting trade, tourism and exports. Such a nation brand will thus be able to uplift the standards of living of the people in the host country. The world has changed. And so must we.

\section{Introduction}

Speaking at the launch of his book on international relations and global politics, this year, British Minister Jim Murphy asserted that "...the world has changed. And so must we. We need a public diplomacy that fits our time, our environment and our challenges. This is an era of global issues, which range from climate security, to threats from avian flu and international terrorism. There are two responses to these global issues. One is to run and, inevitably unsuccessfully and the other is to engage." In the era that we live today, the situation has changed, the market has changed, the players have changed, the media has changed and public diplomacy (PD) too, needs to change.

The continued rise of globalisation catapulted by massive developments in information technology and global mobility of human and capital resources has challenged the way the state relates with other states, local and foreign publics, multi-national corporations and non-governmental organisations. Traditional diplomacy focused on state-to-state relationships and PD focuses on the relationship between the state and other stakeholders across the world. In this global age, the art and practice of PD faces enormous challenges and for the discipline to survive, massive changes are advocated for. One way of ensuring that the nation remains a competitive player on the global market is to integrate PD activities with the novel concept of nation branding. Melissa Aronczyk (2008) posits that "...nation branding as a concept has catapulted the attention - and financial resources - of national governments in countries with established capitalist economies and emerging market economies alike.

In the past few years, countries with such diverse political programmes as Poland, Taiwan, New Zealand and Botswana have jumped to the bandwagon, engaging the profit-based marketing techniques of private enterprise to create and communicate a particular version of national identity." According to Simon Anholt (2006) nation branding is the "...systematic process of aligning the actions, behaviours, investments and communications around a clear strategy for achieving a strengthened competitive identity." All PD activities need to be supported by a good country image and reputation. The establishment of such a "brand" is the essence of nation branding. Reinforcing the same argument, Wally Olins (1999), one of the leading proponents of nation branding, articulates that "... companies and countries are changing fast - and they are becoming more like each other." The advent of globalisation has transformed the way countries are 
managed and a business or market-oriented focus is the key for survival. For a country's PD efforts to be effectively and efficiently implemented there is need to establish a credible and positive nation brand first.

Nation branding, according to Fan (2006), concerns the "...application of branding and marketing communications techniques to promote a nation's image." Such kind of an initiative is the recommended focus of PD in the $21^{\text {st }}$ century, an era that is characterised by hypercompetiton among countries for tourists, export markets, foreign direct investment (FDI), special skills and innovation, leverage in international trade and influence. Besides seeking to create stable relations with other states and partners across the world, PD should also endeavour to market the country abroad. Success on the global market will in turn result in sustained economic growth for the country and an improved quality of life for its citizens.

In light of these developments, the role of government in PD has also been challenged. Instead of being the sole custodian of $\mathrm{PD}$, the new age requires governments across the world to broaden the playing field by facilitating the involvement and participation of non-state actors and private business, national and multi-national, in the country's PD activities. These non-state actors bring the critical mass and expertise required to manoeuvre in the murky waters of global competition.

The current global challenges - more than ever before- call for the state to appreciate the fact that the answers to most of the challenges that the country faces on the global market as well as at the local level - will not only come from the government but also from other stakeholders. The formulation and implementation of effective and sustainable PD programmes is an insurmountable task for the government to go it alone, hence the need for the state to be holistic and inclusive in its approach.

\section{Evolution and Definition of Public Diplomacy}

Although PD has been practiced for over a century, the concept was first defined by Edmund Gullion in 1965 to describe the management of relationships between the state and diverse foreign publics. PD was first introduced in the United States as a government communication strategy during the Cold War era. The concept spread to the United Kingdom, Russia and other countries as the nations battled against each other to demonstrate the supremacy of their political and economic ideologies. Many of its solutions were valid then and the environment has changed. The global age predicates for new approaches to PD.

The Murrow Centre for PD notes that PD "...deals with the influence of public attitude on the formation and execution of foreign policies. It encompasses dimensions of international relations beyond traditional diplomacy; the cultivation by governments of public opinion in other countries; the interaction of private groups and interests in one country with those of another; the reporting of affairs on policy; communication between those whose job is communication, as between diplomats and foreign correspondents; and the process of intercultural communications."

According to McDowell (2008) that when the term PD was coined in the 1960s, it referred to "...the actions of governments to inform and influence foreign publics." This marked a clear formulation and a tidy parallel with traditional diplomacy, "...the aim of which was to directly inform and influence foreign governments." PD can thus be defined as the art and practice of communicating a country's policies, values and culture to other people with the major purpose of building long-term and sustainable socio-economic and political relationships.

From the above definitions, it is more than apparent that the art and practice of PD has become more diverse, more challenging and to the practitioners, more interesting. With the advent of innovative communication technologies and the equally remarkable increase in global mobility and competition the conduct and approach to PD will never be the same again.

\section{Public Diplomacy Today}

According to Bernard Simonin (2008) "...the traditional boundaries of our geopolitical-economic world are being challenged. We have entered an era of hyper-competition and globalisation when the new frontier is found and won in our mental and emotional space." Nations connect with their target audiences both physically emotionally through sociopolitical and business relationships that bring mutual benefits to all the parties. The eradication of national frontiers has led to increasing interconnection and interdependence among states. The role of PD has thus been enlarged to focus more prominently on creating, nurturing and sustaining relationships between governments and their stakeholders across the whole world. These stakeholders include among them the following:

- foreign governments

- international media such as CNN, BBC, Al Jazeera etc 
- global business such as Coca Cola, BP and Shell, Microsoft, and many others.

- non-governmental organisations

- multinational institutions such as the IMF, World Bank, United Nations, African Union and others.

- local and foreign publics

In this "big, yet small global village" the government must reach out to billions of people across the world in its quest to establish and maintain relationships that facilitate the achievement of its foreign and domestic policies and objectives. However, we should not ignore the fact all theses initiatives must be underpinned by national identity and national interest.

\section{Emerging Role of Non-State Actors in Public Diplomacy}

One development that has also emerged in this global age is the shift in the process and ownership of foreign and domestic policy formulation and implementation. As alluded to earlier on, traditional PD has been a sole preserve of the state. However in the global age, non-state actors such as non-governmental organisations, multinational corporations, international media channels, international opinion leaders and the general public are increasingly playing a role in defining and determining the relationship between the state and its local and foreign partners. Because of the complexity and diversity of the global age, the state is challenged to embrace other non-state actors in the determination and management of the country's relationships with other foreign stakeholders.

Secondly, foreign policy is increasingly involving economic and trade issues making it imperative that discussions on foreign policy involve the broader sections of society including business and labour. Ross (2002) elucidates that PD has now undergone a metamorphosis "...from a focus on mainly political objectives through the use of "hard power" (military and economic means) to a more strategic use of "soft power" (understanding and co-operation) to build and sustain long-term and mutually beneficial relationships with bilateral and multilateral partners across the world." Contemporary PD seeks to use credible information to persuade foreign audiences to understand, accept or support the government's policies and actions.

These policies must have the contribution and support of local citizens who are the end-beneficiaries of all PD initiatives. PD is most lively and diverse - and most credible - when it is conducted by governments in cooperation with civil society and other non-state actors to achieve a common and shared agenda. This will thus facilitate the closing of the gap between domestic and foreign policies. PD practitioners can contribute to a nation's soft power through long-term dissemination of the country's culture and values, meticulous explanation of policies, and above all coordination with nonstate actors to deliver credible messages. This development is an indication of a massive shift of power from the ruling elite to the ordinary man on the street although this is not the case with countries that have not yet embraced democratic ideologies and values.

Despite this emerging and irresistible phenomenon, it is equally imperative to highlight that the state remains the primary custodian of State-to-State relations. Much as there is need for the increased involvement and participation of non-state in PD, the activity ultimately remains the ultimate responsibility of the government. Government cannot outsource this relationship but must be able to create a conducive environment for non-state actors' involvement and participation and this is in line with modern democratic tenets.

\section{Public Diplomacy Tools}

In these contemporary times, state and non-state actors have a diversity of public diplomacy tools to choose from and these include:

- Cultural exchanges - e.g. when the Soweto Gospel Choir goes on a World Tour

- International students exchanges - e.g. between SA and German Universities.

- Sports diplomacy - e.g. the Springboks participating in and winning the Tri - Nations Tournament, SA hosting the FIFA 2010 World Cup.

- Trade or business diplomacy - e.g. the India Brazil South Africa (IBSA) discussions.

- Development aid and support - e.g. financial and material support to needy countries such as Mozambique, Zimbabwe and so on.

- Country branding e.g. the South Africa - Alive with Possibility Campaign.

- International communication - e.g. media briefings on CNN, BBC and other media. 


\section{Public Diplomacy and the Information Revolution}

The global age has witnessed unprecedented developments in information communication technologies and this has had a fundamental impact on how public diplomats communicate with their audiences. The advent and continued sophistication of the Internet is one development that public diplomats can only ignore at their own peril.

The internet has emerged as probably the most powerful tool for the dissemination of information across the globe. Almost all state and non-state actors have websites that have information about their history, culture, developments and other successes. The internet allows access to information on a 24-hour-all-year-round basis from any location across the world thereby overcoming time and space differences. One writer noted that "...the new virtual world is democratic. It is an agora. It is a marketplace of ideas." Information, in its abundance and various forms, now travels faster across the world and is available just by the click of a button. This facilitates speedier implementation of communication projects although negative information also benefits from the same development.

The use of the internet in PD is now commonly referred to cyber-public diplomacy. In this information age, as the internet platform continues to develop, more flexible and robust opportunities for information management and dissemination will emerge and the conduct of PD will thus remain on the trot. Internet social networking sites such Facebook, Tweeter, MXit and YouTube are gaining universal recognition as dynamic communication channels.

\section{The Impact of Globalisation on Public Diplomacy}

Living in a "global village" means that countries now share global opportunities and global challenges - hence the need to engage each other in discussing and finding common solutions to common problems. This is the new role of PD in the global age, the need to engage, engage and engage all stakeholders in search for the creation of long lasting relationships that are based on win-win solutions. The following are some of the factors that have impacted on PD as a result of globalisation:

- Growth in global trade hence the need for sustainable and mutually beneficial relationships with targeted partners.

- Access to capital across the globe and hence the need for nations to be investor friendly.

- Ease of travel for public diplomats and the general public

- Foreign policy objectives are increasingly being shaped by views of the international audience. Domestic policies must also be supported by foreign audiences. This therefore supports the call for the closing of the gap between domestic and foreign policies.

- Citizens and non-state institutions are becoming more influential in directing governments' domestic and foreign policies.

- Need to spread the ethos and values of democracy.

- Need to have more friends (partners) than enemies. This helps states to gain economies of scale in production, marketing and influence.

\section{A New Approach to Public Diplomacy}

The ever-changing environment ushered in by globalisation and the subsequent competition among states for resources calls for a paradigm shift in PD. According to Philip Kotler (2002), "... in a world of over six billion people living in nearly 200 countries, the challenge of building a nation's wealth has become a critical business arena." As one of the objectives of PD is to build a socially, politically and economically viable nation, it is imperative for the nation to be able to create a competitive identity or a "nation brand" that enables it to become the country of choice for business and trade on the global market. According to Simon Anholt (2006), "... branding may be seen more as a technique for nations to distinguish themselves in the increasingly competitive international system". Such branding is especially important for poorer and developing countries as it allows them to carve out a particular niche in the global marketplace." Anholt further explains that creating a competitive identity is part of the overall "...plan for mobilizing the strategies, activities, investments, innovations and communications of as many national sectors as possible, both public and private, in a concerted effort to prove to the world that the nation deserves a different, broader and more positive image." This has been the main objective of the South Africa - Alive with Possibility Campaign, but more still needs to be done.

In concurrence with Anholt, Teslik (2007) further elucidates that nation branding efforts have branched out well beyond attracting tourism. Countries now hire firms to help them launch sophisticated branding campaigns aimed at 
luring foreign investment, facilitating trade, improving private sector competitiveness, or even geopolitical influence.

Due to the fact that nations or countries, as a result of globalisation, are now intensely competing with each other, the application of commercial branding techniques to countries has gathered momentum. In this regard, countries have now become 'brands' that can be marketed to a targeted audience in order to achieve desired results. It is this development that calls for the harnessing and integration of PD with nation branding in order to create a competitive and successful "nation brand". All PD activities must be based on or reinforced by a strong nation brand that evokes positive interest and attention across the globe.

\section{Benefits of a Strong Nation Brand}

In an article on the need for Asian countries to re-brand themselves, Temporal (2001) listed the following benefits of a robust and positive national brand image:

- Increases currency stability.

- Helps restore international credibility and investor confidence.

- Reverses international ratings downgrades.

- Increases international political influence.

- Leads to export growth of branded products and services

- Increases inbound tourism and investment.

- Stimulates stronger international partnerships.

- Enhances nation building (confidence, pride, harmony, ambition, national resolve).

- Reverses negative thoughts about environmental and human rights issues.

- Helps diffuse allegations of corruption and cronyism.

- Brings greater access to global markets.

- Leads to an improvement in the ability to win against regional and global business competitors, and defend their own markets.

From the above list of possible benefits, it is evident that nation branding is a powerful concept that can bring enormous benefits to a country. It is also clear that nation branding and public diplomacy to a larger extent seek to achieve the same goals and can thus be synergised. According to Pantzalis and Rodrigues (1999), "... the movement of international capital is influenced by perceptions of countries as brands by investors". They further claim that positioning and managing the country-brand is critical in attracting global capital and affect how and when capital may flee a country in situations such as the 1997 Asian economic crisis.

The flight of investors and the subsequent collapse of the Zimbabwean economy is a classic example of the need for the creation of a strong and positive nation brand, built on a stable foundation of stable domestic and foreign policies. This clearly calls for the synergy of public diplomacy and nation branding for nations to compete successfully on the global market.

\section{The Challenges of Public Diplomacy}

In this global age, PD face enormous challenges and these can be summarised as follows

- The need to develop a shared agenda with global partners - the objective of which should be to create and sustain mutually beneficial or win-win relationships. In cases were there is a conflict of interest, continuous dialogue is the answer.

- Bringing non-state actors on board poses another challenge in terms integrating and coordinating the activities of all the players involved in PD especially if they have different objectives and strategies. The cornerstone of the country's PD initiatives should therefore be the country's national interests and policy objectives.

- The need to be adaptive and robust in light of the never-stopping technological advances. The costs of receiving, sending and processing information have and continue to decrease tremendously. This has resulted in an explosion of information and scarcity of attention as audiences are bombarded with millions of messages everyday by the media and rarely pay attention to any. This calls for effective segmentation and targeting of audiences. Effective nation branding also ensures the creation of a unique and attractive nation brand that captures audience attention in an ocean of competing brands.

- Eradicating global poverty through smart partnerships.

- Reaching out to the general public and ensuring that they are well informed. As pointed out earlier on, policy 
making in many countries is no longer a concern of the select few, it now requires the support of the democratic majority as well as public opinion in most countries. Governments must engage the local and foreign public in the policy formulation phase. They must listen to their voices before developing international policies, signing international laws and agreements. However, achieving public buy-in remains a challenge especially in highly polarised political environments, poor communities and in countries with high levels of illiteracy.

- Creating ongoing dialogue - building up and maintaining a network of contacts. Many public diplomats remain short-sighted, that is, they only look at the short-term benefits and ignore the broader picture and long-term benefits to their countries.

- Building and cultivating a network of contacts in all sectors of society in the country to ensure that the public is well-informed and supportive of the PD initiatives. The public, if buy-in is achieved, become the nation brand ambassadors across the whole world.

- PD should also seek to ensure free trade and flow of resources across the global market. Relationships should be based on mutual understanding and cooperation.

- Struggle for credibility - post-modern publics are generally sceptical of authority and governments are mistrusted. Governments compete for credibility not only with other governments but with a broad range of other alternatives, such as the news media. It is therefore imperative for the government to involve corporates and other non-state actors who generally have more credibility.

- Eradicating conflict and ensuring global peace through negotiations and cooperation

- Transparency, openness, honesty and integrity. PD should move from its traditional culture of secrecy to one of transparency and openness especially in light of the need to bring on board more partners and players. Government should work with other non-state actors in a constructive, transparent and honest way in order to achieve common national objectives.

- Walk the talk - actions speak louder than words. Public diplomats should "practice what they preach" in order to be credible and believable. Honesty and integrity are not optional.

- There is need for strategic leadership in PD. In many countries, the discipline is relegated to lower levels of government work. Surviving in the global age demands that states and non-state actors alike give more prominence to PD activities. PD must therefore be mainstreamed in all government programmes. There is need for an integrated strategy which is supported by a clearly defined national interest.

- Lack of qualified personnel in PD. There is need for the employment of more qualified and experienced PD practitioners in light of the complexity of the field and the challenges it is facing in the global age. The private sector is a good source of expertise.

- Need for public diplomats to be multi-lingual in order to enhance communication and build confidence and trust with their audiences. Currently public diplomats have insufficient language skills to operate effectively on the global market

- Inability to use modern communication technologies. Many public diplomats have not embraced the internet as a communication tool. The internet world of today is one of interactivity and conversation. This has seen the emergence of social networking sites such as Facebook, Mxit, YouTube, My Space and many others. These sites present public diplomats with the opportunity to gain interactive access to global audiences especially the youth, who are the leaders of tomorrow and potential nation brand ambassadors. Surely, any government that resists new Internet techniques faces a greater risk of being ignored.

\section{Conclusion}

In this global age, it is more than apparent that PD will increasingly take on a more strategic role as a domestic and foreign policy instrument in light of the global shift from the use of "hard power" to the use of "soft power" in the establishment, management and sustenance of relationships between the state and other countries, multinational corporations, local and foreign stakeholders. It is therefore imperative for states and non-state actors alike to come together and build a strong nation brand that achieves a competitive edge on the global market. The harnessing and integration of public diplomacy with nation branding, underpinned by a clearly defined national interest, will inevitably be the strategy that differentiates the winners and losers in terms of global market share and the resultant national economic development. Strong nation brands are thus the key for survival in the $21^{\text {st }}$ century and the marriage of PD to nation branding will ensure the building of mutually beneficial relationships and cooperation with global partners to achieve 
sustainable economic development and prosperity. However, for this to become a reality, governments across the world must bring other important partners on-board in domestic and foreign policy formulation in order cross-fertilise ideas, share common problems and come up with common solutions. True to the words of Jim Murphy, one of the main solutions to all the problems facing public diplomacy today is to engage, engage and engage. Without this, the global age will be all gloom and doom.

\section{References}

Anholt, S. 2005. Brand new justice, Revised ed. London: Elsevier Butterworth Heinemann.

Anholt, S. 2006. Editorial. Why Brand? Some practical considerations for nation branding. Place Branding, 2(2): 97- 107.

Anholt, S. 2007. Competitive identity: the new brand management for nations, cities and regions. Basingstoke: Pelgrave Macmillan.

Aronczyk, M. 2008. Living the Brand: Nationality, Globality and the Identity Strategies of Nation Branding Consultants. International Journal of Communication, 2:41 - 65.

Kotler, P., 2002. Country as a brand, product, and beyond: A place marketing and brand management perspective. Journal of Brand Management. 9(4-5): $249-261$.

McDowell. M, 2008. Public Diplomacy at the Crossroads: Definitions and Challenges in an "Open Source "Era, Fletcher Forum of World Affairs, Vol.32:3.

Murphy, J. from <http://www.jimmurphy.com/> (accessed 1 September 2009).

Olins, W. from <http://www. wallyolins.com> (accessed on 3 September 2009).

Pantzalis, J. and Rodrigues, C.A. 1999. Country Names as Brands - Symbolic Meaning and Capital Flows, Montclair State University.

Ross, C. 2002. Public Diplomacy Comes of Age. The Centre for Strategic and international Studies and the Massachusetts Institute of technology, The Washington Quarterly. 25:2.

Simonin, L. B, Nation Branding and Public Diplomacy: Challenges and Opportunities, Fletcher Forum of World Affairs 32(3): 19 - 34

Temporal, P. 2001. Why Asian Countries need Branding on <http://www.asiainc.com/>.

Teslik, L.H. 2007. 'Anholt: Countries Must Earn Better Images through Smart Policy.' Council on Foreign Relations. http://www.cfr.org/publication/14719/. [4 September 2009]

Vatahov, I. 2006. Branding a country. Mass Media Matters, Episode 2:1.

Website of the Edward R. Murrow Centre for Public Diplomacy, The Fletcher School, < http://fletcher.tufts.edu/murrow/> (accessed August 29, 2009). 